\title{
Crustal stress field in Ilan Plain, NE Taiwan and the westernmost Okinawa trough-deduced from seismic stress inversion
}

\author{
Chung-Liang Lo ${ }^{1, *}$, Wen-Nan $\mathrm{Wu}^{2}$, Wen-Bin $\mathrm{Doo}^{3}$, Yin-Shen Huang ${ }^{1}$, and Shu-Kun Hsu ${ }^{1,3}$ \\ ${ }^{I}$ Department of Earth Sciences, National Central University, Taoyuan City, Taiwan \\ ${ }^{2}$ College of Oceanography, Hohai University, Nanjing, China \\ ${ }^{3}$ Center for Environmental Studies, National Central University, Taoyuan City, Taiwan
}

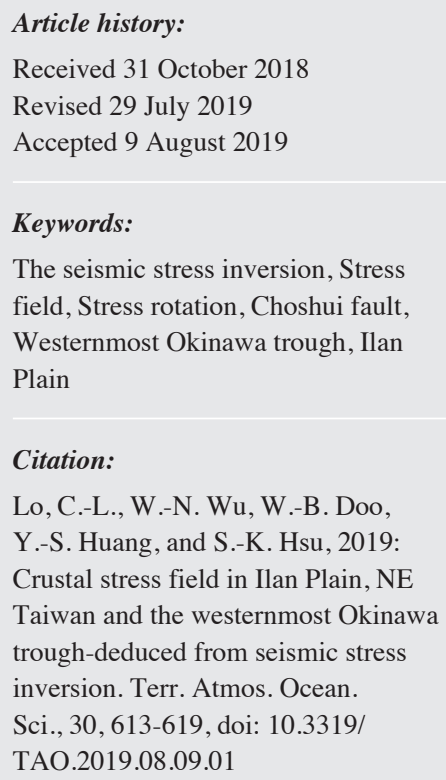

Citation:

Lo, C.-L., W.-N. Wu, W.-B. Doo, Y.-S. Huang, and S.-K. Hsu, 2019: Crustal stress field in Ilan Plain, NE Taiwan and the westernmost Okinawa trough-deduced from seismic stress inversion. Terr. Atmos. Ocean. Sci., 30, 613-619, doi: 10.3319/ TAO.2019.08.09.01

\begin{abstract}
The tectonic stress in the Ilan Plain (IP), NE Taiwan region is complex. Because the Philippine Sea plate converges and subducts beneath the Eurasian plate, and the Okinawa trough is rifting westward. We adopt the focal mechanisms collection during the period $1996-2016$ to invert the stress field in the crust with grid of $0.1^{\circ}$ by $0.1^{\circ}$. Most of the focal mechanisms in the crust occurred in the shallow $15-\mathrm{km}$ depth. The stress inversion result shows that the dominant stress in this region is of extension $\left(\sigma_{3}\right)$ in the NW-SE direction and with a clockwise rotation in the southeast part. On the contrary, the compressional stress $\left(\sigma_{1}\right)$ is relatively complex in the same IP region and can essentially be divided into three parts: (1) offshore the IP, mostly east of $121.95^{\circ} \mathrm{E}$, the $\sigma_{1}$ is quite stable in the about N-S direction; (2) it behaves unstable and large uncertainty in the NW-SE direction in the northern flank of the IP; and (3) the $\sigma_{1}$ remains stable in the southern wing of the IP and is oriented in the NE-SW direction, except for two W- and E-end. The different states and stability distributions of the $\sigma_{1}$ stress axis between the north and south IP is clear, which implies that this could be caused by some potential structures or stress divisions. The left-lateral strike-slip Choshui crosscutting through the middle IP may be the corresponding structure in line with the preceding stress barrier.
\end{abstract}

\section{INTRODUCTION}

The Ryukyu subduction zone extends from Japan to eastern Taiwan, where the Philippine Sea plate (PSP) subducts beneath the Eurasian plate (EU) and the Okinawa trough (OT) rifts behind the Ryukyu arc (Letouzey and Kimura 1986; Sibuet et al. 1987; Liu 1995). Tectonics in northeastern Taiwan region is therefore complex. Morphologically, the westernmost end of the OT stops at east of $123^{\circ} \mathrm{E}$, and there is little evidence showing that the OT extends westward. The Ilan plain (IP), in northeastern Taiwan, is generally considered as the result of westward continuous opening of the OT. An evident observation is the low gravity anomaly signal elongated from the IP on land to its northeastern offshore (Doo et al. 2018). This phenomenon is attributed to the thinning of the crust and thickening of the sediment in the IP area. Besides, the series of active micro-

\footnotetext{
* Corresponding author

E-mail:lo.chungliang@gmail.com
}

seismicity and volcanism in the southwestern OT has also been reported from ocean bottom seismometer experiments (e.g., Lin et al. 2007, 2009). The seismicity in this region concentrates at two parts: (1) mainly normal faulting with some strike-slip earthquakes in the shallow depth $(<15 \mathrm{~km})$ (Fig. 1), and (2) thrust faulting with some strike-slip earthquakes along with the subducting slab in depths $(>50 \mathrm{~km})$ (Wu et al. 2010b). In this study, we focus on the crustal stress field so that the deep seismicity associated with the PSP slab subducting will not be included for discussion.

The Lanyang River flows through the whole IP from west and into the sea to the east and separates the IP into north and south parts. Several faults were developed in the plain. Amongst, the Choshui fault (CF) in the south central part of the IP, close to the Lanyang River, is the longest and cuts through the plain (Fig. 1). It is believed extending from the Lishan fault in the west, a boundary between the Hsuehshan Range (HR) and the Central Range (CR) (Biq 


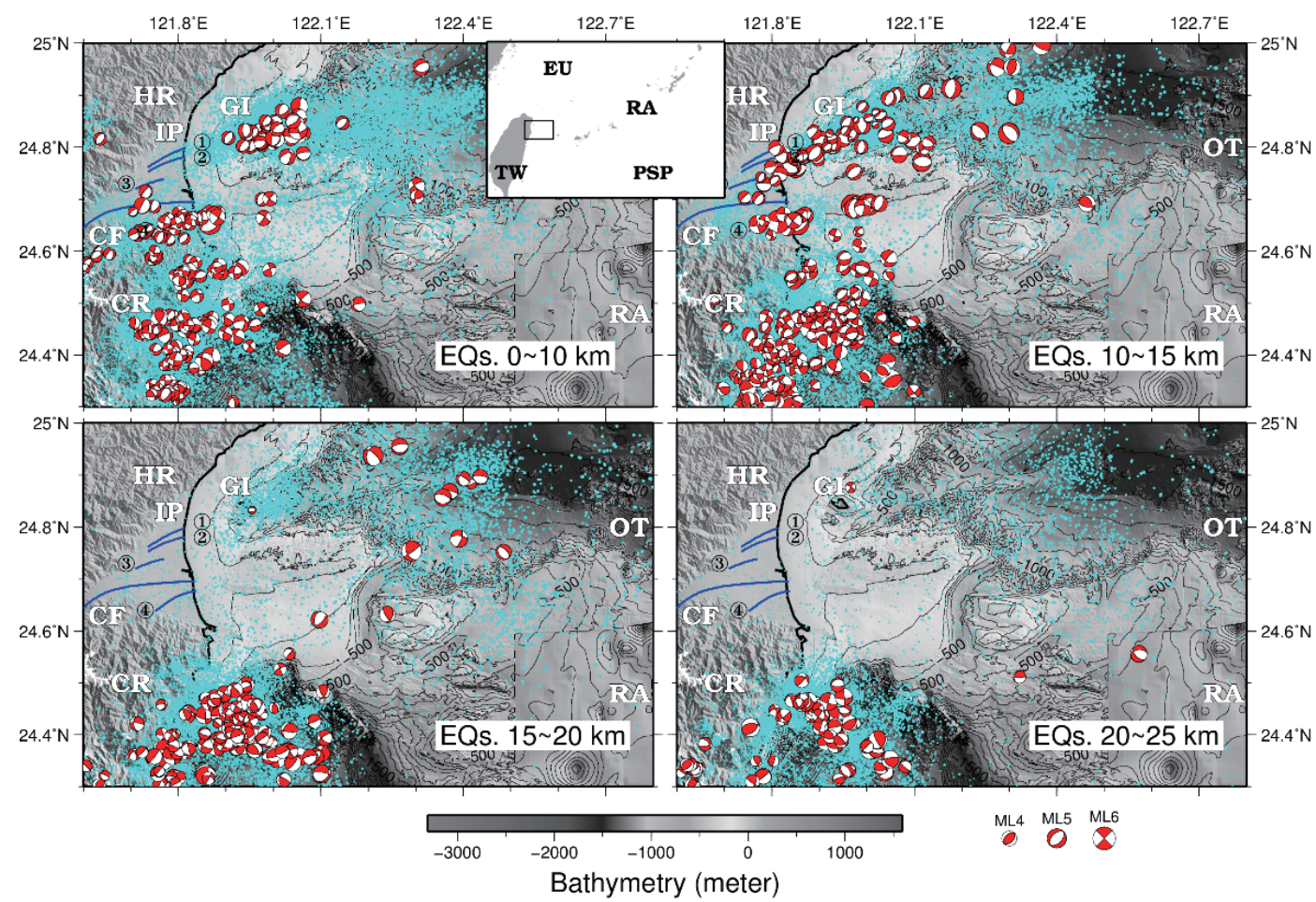

Fig. 1. The seismicity distribution in the Ilan Plain, northeastern Taiwan and the westernmost Okinawa trough. Most of the seismicity occurred mainly within $15 \mathrm{~km}$ of depth, and less and less focal mechanism becomes available deeper than $15 \mathrm{~km}$. Cyan dots are the background seismicity. Blue solid lines indicate the buried faults derived from Jhiang (1976): (1) the Yaichein fault; (2) the Ilan fault; (3) the Kengssu fault; (4) the Sansing fault. CF: Choshui fault; CR: Central Range; GI: Guishan Island; HR: Hsuehshan Range; IP: Ilan Plain; OT: Okinawa trough; RA: Ryukyu arc.

1971; Tsan 1971) (Fig. 1). However, the seismicity along the $\mathrm{CF}$ is not obvious, while the seismicity at its southern Sansing fault (SF) is more active. Some shorter and minor faults are in the north IP, their seismicity is not so active (Jhiang 1976).

In previous studies, the GPS observations in Taiwan region help a lot for crustal deformation estimation (e.g., Yu et al. 1997; Bos et al. 2003; Chang et al. 2003; Hsu et al. 2009; Chen et al. 2017). The induced stress or strain rate field in the IP area presented one general consistent NW-SE extension orientation. Rau et al. (2008) and Rateb et al. (2017) used blocks model constrained by major faults to describe the crustal deformation kinematics, they have the similar result and both provide the clockwise crustal rotation in the south IP blocks. A better resolution of strain rate and rotation rate fields were obtained that benefits from the local "Ilan GPS network" observation between 2002 and 2006 by the Central Geological Survey, Ministry of Economic Affairs (Hou et al. 2009). An evident deformation of crustal dilatation, with NW-SE extension and orthogonal contraction, was investigated in the south IP and strengthened close to the southeast corner of the IP. The crustal dilatation becomes minor westward and northward, and almost insignificant in the north IP. The rotation rate field displays a pronounced clockwise rotation pattern at the southeast tip of the IP and at the northern end of its neighboring CR. The crustal rotation pattern becomes counterclockwise and is prominent in the E-W central-axis banding of the IP. At the north edge of the IP, the rate of crustal rotation is reduced to insignificant (Hou et al. 2009).

In view of variant crustal deformation patterns observed in the IP, the corresponding stress field should be evaluated to verify such behaviors. Wu et al. (2010a) have proposed the stress field along the Ryukyu Subduction zone through Taiwan collision zone to the Manila subduction zone using the seismic stress inversion method. Their result shows that the $\sigma_{3}$ is in NW-SE direction in the IP and offshore areas while the $\sigma_{1}$ is in NE-SW and E-W direction. The similar stress field in the IP and offshore region is also acquired, e.g., by Wu et al. (2010b) and Huang et al. (2012) from seismic data, and strain field by Chang et al. (2003) and Hsu et al. (2009) from geodetic data. The stress inversion estimation with gridding size of $0.25^{\circ}$ for the whole Taiwan region is good enough in resolution reported in $\mathrm{Wu}$ et al. (2010a), but for the IP local area is relatively large and cannot distinguish the stress variation. In order to solve a more detailed stress field, the study area will be divided into finer grid size as $0.1^{\circ}$ by $0.1^{\circ}$. It will help better understand the joint stress regime exerted by the convergence between the PSP and the EU, and the OT rifting. 


\section{EARTHQUAKE DATA AND THE STRESS INVERSION METHOD}

Two earthquake data sets during 1990 to 2016 that resolved by $\mathrm{Wu}$ et al. (2008) (downloaded from http:// seismology.gl.ntu.edu.tw/download.htm) are used in this study. One is a high-resolution seismicity catalog which is relocated by $3 \mathrm{D}$ velocity model and used to illustrate the seismogenic structures. Another is the first-motion focal mechanism catalog used to perform the stress tensor inversion. This focal mechanism catalog provides not only the smaller-size earthquakes but also reliable relocated location (Wu et al. 2008).

Because our target is to study the crustal-scale stress field and we find that the most earthquakes occurred shallower than $15 \mathrm{~km}$, the focal depth of $15 \mathrm{~km}$ is used to select crustal earthquakes. In total, 258 events were used for further analysis (Fig. 2).

The method used to determine the crustal stress field is the damped stress inversion method that introduced a damping parameter to minimize the difference between the stress tensors at two neighboring grid nodes (Hardebeck and Michael 2006). The major advantage of using the damped stress inversion algorithm is to prevent from the subjective data selection. The procedures to determine the stress tenors in practice follow the works in Wu et al. (2010a, 2017). By additional examinations on dataset, we can provide more robust stress inversion result. The studied area was divided into $0.1^{\circ}$ by $0.1^{\circ}$ grid, and each focal mechanism solution was assigned to the nearest grid node (Fig. 2a). The number of events for each grid node is shown in Fig. $2 b$, and grid nodes with at least eight events were used for the stress tensor inversion. There are more than eight events in a grid node, which is enough for the needed number of used events in the stress inversion algorithm and provides the robust inversion result. The average focal depth for each grid node is between 7 and $14 \mathrm{~km}$ (Fig. 2c). It is well known that a set of appropriate focal mechanisms (i.e., the focal mechanism diversity) is necessary to offer the promise of performing the stably stress inversion (Hardebeck and Michael 2006). The focal mechanism diversity is determined by calculating the average focal mechanism for a set of fault plane solutions and computing the root-mean-square value of angular differences between the average focal mechanism and each fault plane solution (Hardebeck and Michael 2006). Hardebeck and Michael (2006) also demonstrated that the focal mechanism diversity must be large enough $\left(\geq 45^{\circ}\right)$ for the focal mechanisms with $20^{\circ}$ uncertainty so that the stress inversion result will be more reliable. The average error of our input focal mechanisms is about $17^{\circ}$, we marked the grid nodes with different colors to present the focal mechanism diversity (Fig. 2d).

For the damped stress inversion, we first tested a series of damping parameters to obtain the L-curve that represents the trade-off between the model length and the data variance. As shown in Fig. 3, the optimal damping value is a value of 1.0 which is at the corner off the L-curve and has minimum values of both model length and data variance.

\section{SEISMIC STRESS INVERSION RESULT}

The outputs of the damped stress tensor inversion are the azimuths and plunges of the three principle stress axes, $\sigma_{1}, \sigma_{2}$, and $\sigma_{3}\left(\sigma_{1} \geq \sigma_{2} \geq \sigma_{3}\right)$, the stress ratio $\left[\phi=\left(\sigma_{2}-\sigma_{3}\right) /\right.$ $\left.\left(\sigma_{1}-\sigma_{3}\right)\right]$ and the corresponding $95 \%$ confidence level from 1000 bootstrap re-samples for each grid node. Conventionally, the maximum principle axis $\left(\sigma_{1}\right)$ is defined as the compressional stress axis, and the minimum stress axis $\left(\sigma_{3}\right)$ is the extensional stress axis (Angelier 1979).

Our inverted stress results, as shown in Fig. 4, provide the resolution as high as $0.1^{\circ}$ for delineating the spatial variations of the stress tensors in the westernmost OT and the IP in northeastern Taiwan. Figure 4a illustrates that the stress state of the inverted stress orientations in terms of the equalarea projections of the lower hemisphere of the focal sphere. Overall, our results show that the stress state is dominated by the NW-SE extension normal faulting in most areas of the IP and its offshore with high confidence (Figs. 4a and c), while it is governed by the left-lateral strike-slip mechanisms in the southeastern IP and its offshore areas (Fig. 4a). It also indicates that the IP undertakes a quite stable dominant extensional stress field. This result should correspond to the westward extension of the OT rifting (Liu 1995), and implies that the rifting of the OT is obviously the fundamental driving force. Besides, the azimuth of the $\sigma_{3}$ with clockwise rotation is more evident from inland approaching to offshore in southeastern corner (Fig. 4c).

To the $\sigma_{1}$ (see Fig. 4b), it is not as identical as the $\sigma_{3}$ component, but complicated actually. Prominently, the $\sigma_{1}$ displays a discrepancy between the northern and southern IP close to $\sim 24.7^{\circ} \mathrm{N}$. In northern part, the $\sigma_{1}$ direction shows unstable and variant while it becomes a stable NE-SW direction in southern part. As preceding mentioned, the inverted stress state (Fig. 4a) shows a different stress regime on both sides at $\sim 24.7^{\circ} \mathrm{N}$. In addition, in most areas, the $\sigma_{1}$ direction has high angle plunge to the surface, except that it is close to horizontal in the southern IP (south of $24.7^{\circ} \mathrm{N}$ ) (Fig. 4a). Consequently, the inconsistent stress direction and different stability on the north and south sides of the IP indicate that the stress $\sigma_{1}$ is different on both sides. Another distinct $\sigma_{1}$ difference displays on both sides along $121.95^{\circ} \mathrm{E}$ and extends to the Guishan Island to the north. On the east side, the $\sigma_{1}$ direction is in a steady $\sim \mathrm{N}-\mathrm{S}$ trending and totally different from that on its west side. This indicates that the situation of different stress on both sides of the IP may stop at $121.95^{\circ} \mathrm{E}$ and no longer extend eastward. The distribution of focal mechanism in shallow depth $(<15 \mathrm{~km})$ also shows a clear gap in the corresponding area (Fig. 1). The segmented 
(a) Distribution of Earthquakes

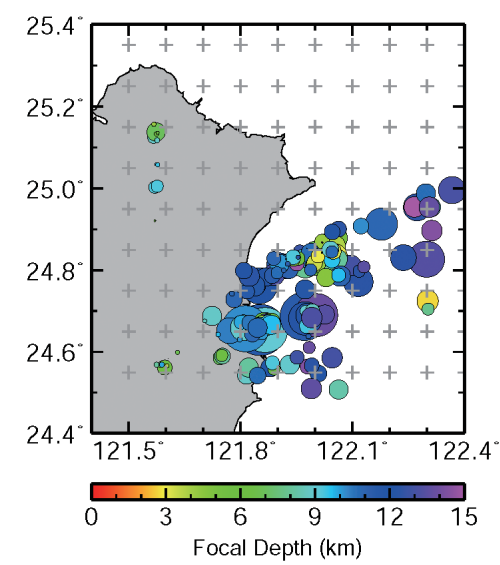

(c) Average Focal Depth

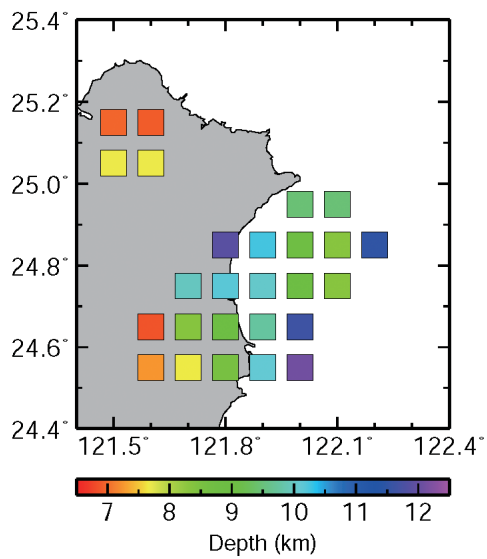

(b) Event Density

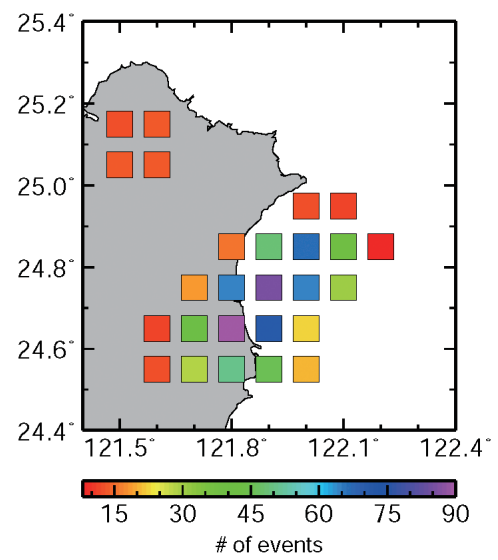

(d) Focal Mechanism Diversity

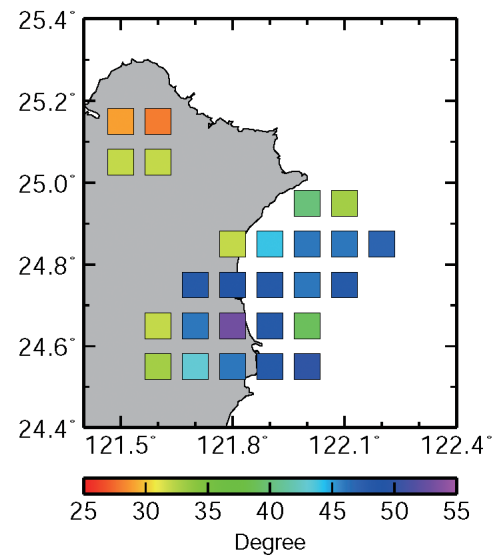

Fig. 2. (a) Distribution of grid node and selected focal mechanisms used in the stress inversion; (b) the event density (numbers) meets the criteria; (c) distribution of average focal depth; (d) distribution of focal mechanism diversity in each grid.

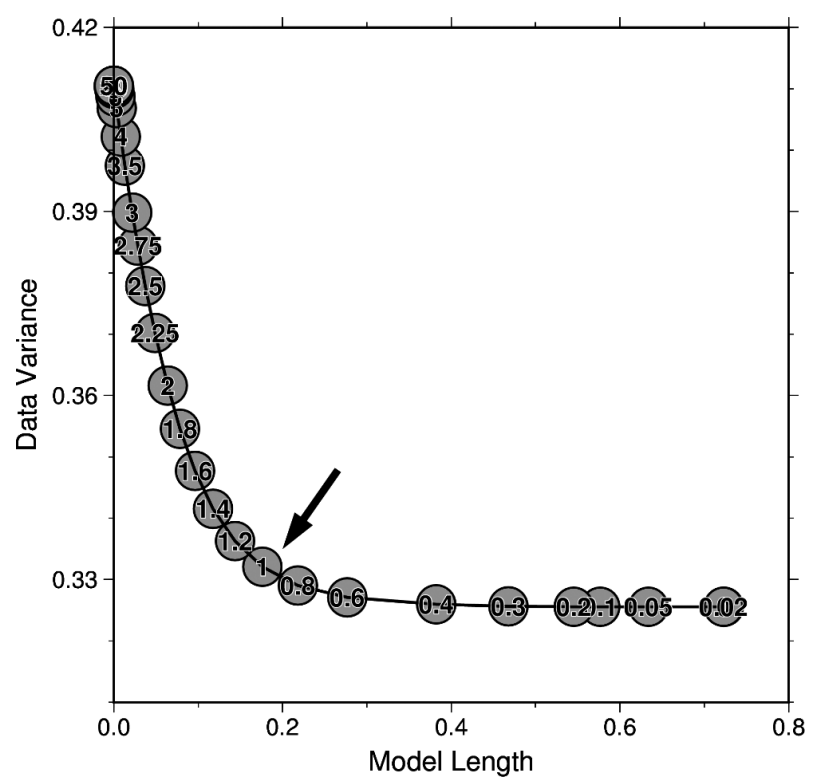

Fig. 3. Trade-off curves shows the relation between the model length and data variance for different choices of the damping parameters. The value used in our final inversion are marked by the solid black arrow. 
(a) Inverted Stress State

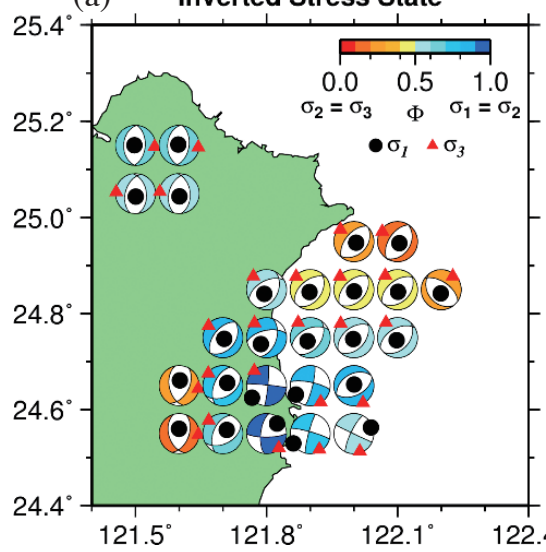

(b) $95 \%$ confidence interval for $\sigma_{1}$

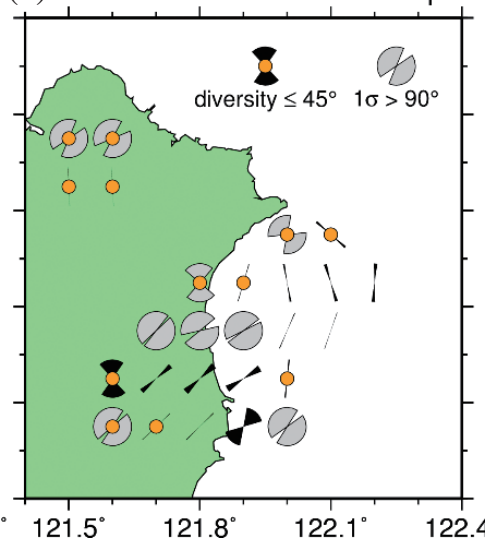

(c) $95 \%$ confidence interval for $\sigma_{3}$

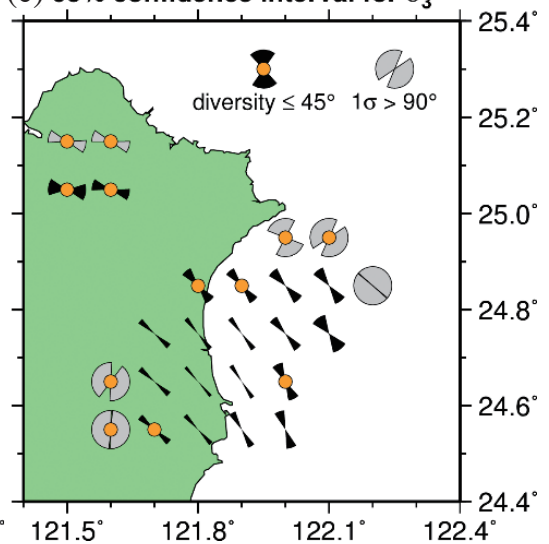

Fig. 4. The stress inversion result displays in (a) the inverted stress status; (b) the $95 \%$ confidence interval for the $\sigma_{1}$ directions; (c) same as (b) but for the $\sigma_{3}$.

stress pattern distribution in this area implies that this could be caused by some potential structures or stress divisions.

\section{DISCUSSION AND CONCLUSION}

In previous studies, the stress status in the IP all shows the NW-SE extension and contraction in the NE-SW direction (Hsu et al. 2009; Wu et al. 2010a, b). They have a common stress state compared to our results, but they can only show a general feature in a larger range. Chen et al. (2017) showed more details using the same grid size as ours $\left(0.1^{\circ} \times\right.$ $\left.0.1^{\circ}\right)$. Except for the large uncertainties of seismic $\sigma_{1}$ were observed in the northern IP, the $\sigma_{1}$ axes are stable in the NESW direction in the southern IP, which is similar to the comparison result between the geodetic and seismic compressional axes $(<20 \mathrm{~km})$ in Chen et al. (2017) (Figs. 4a and b). This comparison also suggests that the results in the southern IP from two different independent dataset are compatible. In addition, the advantage of using the seismic data to perform the seismic stress inversion method can make up the lack of the marine geodetic observations in the offshore IP area.

For the north side of the IP, a discrepancy is displayed between our inverted seismic stress results and the previous geodetic observations (e.g., Hsu et al. 2009; Chen et al. 2017). Large uncertainty of the inverted seismic $\sigma_{1}$ indicates that there should be underwent multiple driving force in this segment. In other words, there should be at least two driving force or a stress barrier separating the IP into north and south parts. As previous mentioned, the stress state result (Fig. 4a) have shown that the different stress mechanisms is divided by $\sim 24.7^{\circ} \mathrm{N}$. The location of stress division coincides with the CF. The obvious separation feature of two different types of stress state extends eastward and stops at $\sim 121.95^{\circ} \mathrm{E}$ implying that the $\mathrm{CF}$ could be terminated there. Due to the lack of evidence, the continuity of the CF from land to sea is unknown and needs further exploration.
In addition, this stress boundary is also emphasized by the stress rotation of the $\sigma_{3}$ in the right panel in Fig. 5. Taking $121.7^{\circ} \mathrm{E}, 24.7^{\circ} \mathrm{N}$ as the reference point, it is between the two most consistent points of azimuth of the $\sigma_{3}$ at the western edge in this study. The azimuth of the $\sigma_{3}$ of the reference point is $\sim 130^{\circ}$. Overall, the stress axis of the $\sigma_{3}$ in the IP and offshore region behaves clockwise rotation, and becomes apparent across $24.7^{\circ} \mathrm{N}$ from north while it approaches to the southeastern offshore. The largest rotation angle is $\sim 31^{\circ}$ at $122^{\circ} \mathrm{E}, 24.55^{\circ} \mathrm{N}$. Consistent dominant NW-SE extension stress associated with the stable $\sigma_{3}$ in southern IP and its adjacent areas, which indicates that the clockwise stress rotation may be led from the total effects of the OT rifting and the northern CR lateral extrusion (Hou et al. 2009; Huang et al. 2012; Wu et al. 2014).

A clear spatial variation of crustal deformation is remarkable in the IP. Hou et al. (2009) proposed the evident crustal rotational difference via the observed GPS velocity field (Fig. 5). In the southern part of the IP and northernmost part of the CR show the great clockwise rotation, which agrees well with our result. However, the seismic stress rotation of the $\sigma_{3}$ is different from that the surface rotates counterclockwise in the central-axis banding of the IP from western tip to the coast end (Fig. 5). To the northern corner of the IP, the status of the crustal rotation becomes minor and insignificant, but reverts to clockwise deformation again. The position of the two seismic linear activities entering the IP is in good agreement with the permutation of crustal deformation from geodetic observation (Fig. 1 and the left panel in Fig. 5). A linear seismicity extended from the Guishan Island swarm cuts through into the central IP from offshore. It divides the northern flank of the IP crust with insignificant clockwise deformation from the anticlockwise deformation in the central-axis banding of the IP (Fig. 5). Another shorter linear seismicity cuts through the southern IP that confines the crust anticlockwise rotation in the central-axis part of 


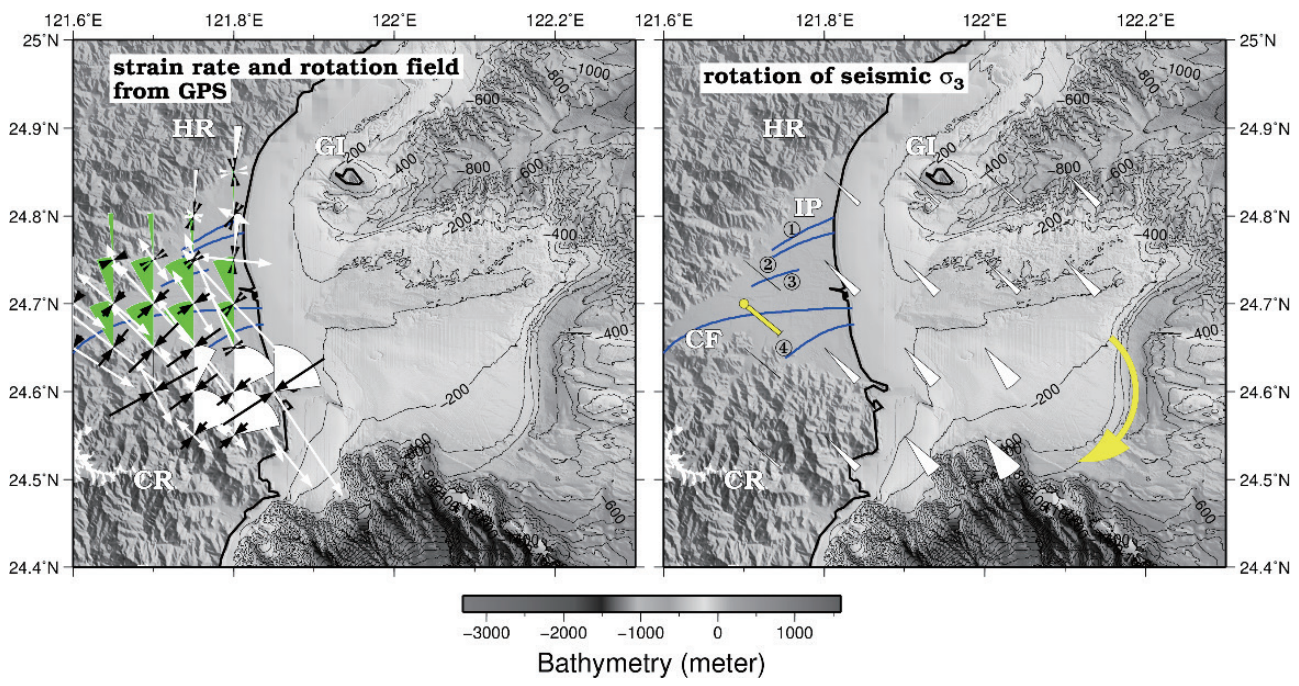

Fig. 5. The strain rate and rotation field observed from GPS (data adopted from Hou et al. 2009) in left panel. Fan-shape wedges in white represent clockwise rotation while that in green rotate counterclockwise. Thin white arrows represent extension and black thin arrows are for contraction. In the right panel, it shows the rotation of the $\sigma_{3}$ from Fig. $4 \mathrm{c}$. The rotation result takes reference to the point at $121.7^{\circ} \mathrm{E}, 24.7^{\circ} \mathrm{N}(\mathrm{yellow}$ point with a thin bar), which is between the two most consistent points of azimuth of the $\sigma_{3}$ at the western edge in this study. The azimuth of the $\sigma_{3}$ at the reference point is $\sim 130^{\circ}$.

the IP. This linear seismicity corresponds to the location of the Sansing fault (Figs. 1 and 5). To the south of SF, the evident clockwise rotation of crustal deformation appears. This observation represents that the SF is a left-lateral strikeslip structure and results in an anticlockwise rotation in the middle IP segment and clockwise rotation in the south IP flank (Jhiang 1976). In terms of the surface deformation, the Sansing fault is a deformation boundary. For stress boundary, the Choshui fault could be regarded as the corresponding structure. The different boundaries between the strain (rotation) and the stress field are limited by the position of the calculating grid.

Using the 1990 - 2016 seismic data catalogue with fine grid of $0.1^{\circ}$ by $0.1^{\circ}$, the crustal stress field in the Ilan Plain and its offshore areas was estimated by the seismic stress inversion method. The seismicity in the crust mainly occurred shallower than $15 \mathrm{~km}$ in depth and are of extensional faulting types. The stress inversion result shows that the dominant stress in this region is of extensional state in the NW-SE direction stably, apparently dominated by the rifting force of the Okinawa trough. Moreover, it is accompanied by a clockwise rotation to the southeast offshore. In contrast, the compressive stress $\sigma_{1}$ orientation in this region is more complicated. Close to the Guishan Island and to the east side of $121.95^{\circ} \mathrm{E}$, the $\sigma_{1}$ direction is evident and basically in the N-S direction. To the north of the Choshui fault, the uncertainty of the $\sigma_{1}$ orientation becomes large, and basically in the average NW-SE direction. To the southern Ilan Plain and the northernmost Central Range (south of the Choshui fault), the $\sigma_{1}$ restores stable NE-SW orientation suggesting that a constant lateral extrusion deformation works here. Consequently, the abrupt change of the seismic $\sigma_{1}$ orientation between the northern and southern part of the Ilan Plain indicates that the left-lateral strike-slip Choshui fault plays a corresponding important stress division boundary. Overall, the seismic stress inversion result is well consistent with the GPS observation in the southern part of the Ilan Plain and its adjacent areas. The stable stress state of the $\sigma_{3}$ and its clockwise stress rotation may come from the combination effect, which is the lateral extrusion by the compressed Central Range due to the convergence between the PSP and the EU, and involving with the rifting force of the Okinawa trough.

Acknowledgements We thank Dr. Yih-Min Wu for making the relocated seismicity catalog and first-motion focal mechanisms available. The authors also thank the two reviewers for their valuable comments and suggestions to help improve this article. All figures were made by the Generic Mapping Tools (Wessel and Smith 1998). This study was supported by the Ministry of Science and Technology (MOST) of Taiwan under grant MOST 107-2811-M-008-025.

\section{REFERENCES}

Angelier, J., 1979: Determination of the mean principal directions of stresses for a given fault population. Tectonophysics, 56, T17-T26, doi: 10.1016/00401951(79)90081-7. [Link]

Biq, C., 1971: Some aspects of post-orogenic block tectonics in Taiwan: Recent crustal movements. Royal Soc. New Zealand Bull., 9, 19-24.

Bos, A. G., W. Spakman, and M. C. J. Nyst, 2003: Surface deformation and tectonic setting of Taiwan inferred 
from a GPS velocity field. J. Geophys. Res., 108, doi: 10.1029/2002JB002336. [Link]

Chang, C.-P., T.-Y. Chang, J. Angelier, H. Kao, J.-C. Lee, and S.-B. Yu, 2003: Strain and stress field in Taiwan oblique convergent system: Constraints from GPS observation and tectonic data. Earth Planet. Sci. Lett., 214, 115-127, doi: 10.1016/S0012-821X(03)00360-1. [Link]

Chen, S. K., Y.-M. Wu, Y.-J. Hsu, and Y.-C. Chan, 2017: Current crustal deformation of the Taiwan orogen reassessed by cGPS strain-rate estimation and focal mechanism stress inversion. Geophys. J. Int., 210, 228-239, doi: 10.1093/gji/ggx165. [Link]

Doo, W.-B., C.-L. Lo, S.-K. Hsu, C.-H. Tsai, Y.-S. Huang, H.-F. Wang, S.-D. Chiu, Y.-F. Ma, and C.-W. Liang, 2018: New gravity anomaly map of Taiwan and its surrounding regions with some tectonic interpretations. J. Asian Earth Sci., 154, 93-100, doi: 10.1016/j. jseaes.2017.12.010. [Link]

Hardebeck, J. L. and A. J. Michael, 2006: Damped regional-scale stress inversions: Methodology and examples for southern California and the Coalinga aftershock sequence. J. Geophys. Res., 111, doi: 10.1029/2005JB004144. [Link]

Hou, C.-S., J.-C. Hu, K.-E. Ching, Y.-G. Chen, C.-L. Chen, L.-W. Cheng, C.-L. Tang, S.-H. Huang, and C.-H. Lo, 2009: The crustal deformation of the Ilan Plain acted as a westernmost extension of the Okinawa Trough. Tectonophysics, 466, 344-355, doi: 10.1016/j.tecto.2007.11.022. [Link]

Hsu, Y.-J., S.-B. Yu, M. Simons, L.-C. Kuo, and H.-Y. Chen, 2009: Interseismic crustal deformation in the Taiwan plate boundary zone revealed by GPS observations, seismicity, and earthquake focal mechanisms. Tectonophysics, 479, 4-18, doi: 10.1016/j.tecto.2008.11.016. [Link]

Huang, H.-H., J. B. H. Shyu, Y.-M. Wu, C.-H. Chang, and Y.-G. Chen, 2012: Seismotectonics of northeastern Taiwan: Kinematics of the transition from waning collision to subduction and postcollisional extension. J. Geophys. Res., 117, doi: 10.1029/2011JB008852. [Link]

Jhiang, S.-C., 1976: Seismic study of the Ilan Plain. Min. Tech. Dig., 14, 215-221. (in Chinese)

Letouzey, J. and M. Kimura, 1986: The Okinawa Trough: Genesis of a back-arc basin developing along a continental margin. Tectonophysics, 125, 209-230, doi: 10.1016/0040-1951(86)90015-6. [Link]

Lin, J.-Y., J.-C. Sibuet, C.-S. Lee, S.-K. Hsu, and F. Klingelhoefer, 2007: Origin of the southern Okinawa Trough volcanism from detailed seismic tomography. J. Geophys. Res., 112, doi: 10.1029/2006JB004703. [Link]

Lin, J.-Y., J.-C. Sibuet, C.-S. Lee, S.-K. Hsu, F. Klingelhoefer, Y. Auffret, P. Pelleau, J. Crozon, and C.-H. Lin, 2009: Microseismicity and faulting in the south- western Okinawa Trough. Tectonophysics, 466, 268280, doi: 10.1016/j.tecto.2007.11.030. [Link]

Liu, C.-C., 1995: The Ilan Plain and the southwestward extending Okinawa Trough. J. Geol. Soc. China, 38, 229-242.

Rateb, A., K.-E. Ching, C.-Y. Kuo, R.-J. Rau, and C.-L. Chen, 2017: Kinematics of the tectonic blocks and active faults at the post-orogenic stage: Northern Taiwan. J. Asian Earth Sci., 149, 29-40, doi: 10.1016/j. jseaes.2017.07.055. [Link]

Rau, R.-J., K.-E. Ching, J.-C. Hu, and J.-C. Lee, 2008: Crustal deformation and block kinematics in transition from collision to subduction: Global positioning system measurements in northern Taiwan, 1995-2005. J. Geophys. Res., 113, doi: 10.1029/2007JB005414. [Link]

Sibuet, J.-C., J. Letouzey, F. Barbier, J. Charvet, J.-P. Foucher, T. W. C. Hilde, M. Kimura, L.-Y. Chiao, B. Marsset, C. Muller, and J.-F. Stéphan, 1987: Back Arc Extension in the Okinawa Trough. J. Geophys.Res., 92, 14041-14063, doi: 10.1029/JB092iB13p14041. [Link]

Tsan, S. F., 1971: Structural Geology of the southern Hsuehshan Range, Taiwan. Proc. Geol. Soc. China, 14, 62-75.

Wessel, P. and W. H. F. Smith, 1998: New, improved version of generic mapping tools released. Eos, Trans. $A G U, 79,579$, doi: 10.1029/98EO00426. [Link]

Wu, F. T., H. Kuo-Chen, and K. D. McIntosh, 2014: Subsurface imaging, TAIGER experiments and tectonic models of Taiwan. J. Asian Earth Sci., 90, 173-208, doi: 10.1016/j.jseaes.2014.03.024. [Link]

Wu, W.-N., H. Kao, S.-K. Hsu, C.-L. Lo, and H.-W. Chen, 2010a: Spatial variation of the crustal stress field along the Ryukyu-Taiwan-Luzon convergent boundary. $J$. Geophys. Res., 115, doi: 10.1029/2009JB007080. [Link]

Wu, W.-N., C.-L. Lo, and J.-Y. Lin, 2017: Spatial variations of the crustal stress field in the Philippine region from inversion of earthquake focal mechanisms and their tectonic implications. J. Asian Earth Sci., 142, 109118, doi: 10.1016/j.jseaes.2017.01.036. [Link]

Wu, Y.-M., L. Zhao, C.-H. Chang, and Y.-J. Hsu, 2008: Focal-Mechanism Determination in Taiwan by Genetic Algorithm. Bull. Seismol. Soc. Am., 98, 651-661, doi: 10.1785/0120070115. [Link]

Wu, Y.-M., Y.-J. Hsu, C.-H. Chang, L. S. Teng, and M. Nakamura, 2010b: Temporal and spatial variation of stress field in Taiwan from 1991 to 2007: Insights from comprehensive first motion focal mechanism catalog. Earth Planet. Sci. Lett., 298, 306-316, doi: 10.1016/j. eps1.2010.07.047. [Link]

Yu, S.-B., H.-Y. Chen, and L.-C. Kuo, 1997: Velocity field of GPS stations in the Taiwan area. Tectonophysics, 274, 41-59, doi: 10.1016/S0040-1951(96)00297-1. [Link] 